\title{
Valerenic acid and Valeriana officinalis extracts delay onset of Pentylenetetrazole (PTZ)-Induced seizures in adult Danio rerio (Zebrafish)
}

\author{
Bianca A. Torres-Hernández ${ }^{*}$ Lisa M. Del Valle-Mojica and José G. Ortíz
}

\begin{abstract}
Background: Anticonvulsant properties have been attributed to extracts of the herbal medicine Valeriana officinalis. Our aims were to examine the anticonvulsant properties of valerenic acid and valerian extracts and to determine whether valerian preparations interact with the activity of other anti-epileptic drugs (phenytoin or clonazepam). To achieve these goals, we validated the adult zebrafish, Danio rerio, as an animal model for studying anticonvulsant drugs.

Methods: All drug treatments were administered by immersion in water containing the drug. For assays of anticonvulsant activity, zebrafish were pretreated with: anti-epileptic drugs, valerenic acid, aqueous or ethanolic valerian extracts, or mixtures (phenytoin or clonazepam with valerenic acid or valerian extracts). Seizures were then induced with pentylenetetrazole (PTZ). A behavioral scale was developed for scoring PTZ-induced seizures in adult zebrafish. The seizure latency was evaluated for all pretreatments and control, untreated fish. Valerenic acid and both aqueous and ethanolic extracts of valerian root were also evaluated for their ability to improve survival after pentylenetetrazolechallenge. The assay was validated by comparison with well-studied anticonvulsant drugs (phenytoin, clonazepam, gabapentin and valproate). One-way ANOVA followed by Tukey post-hoc test was performed, using a $p<0.05$ level of significance. All treatments were compared with the untreated animals and with the other pretreatments.

Results: After exposure to pentylenetetrazole, zebrafish exhibited a series of stereotypical behaviors prior to the appearance of clonic-like movements - convulsions. Both valerenic acid and valerian extracts (aqueous and ethanolic) significantly extended the latency period to the onset of seizure (convulsion) in adult zebrafish. The ethanolic valerian extract was a more potent anticonvulsant than the aqueous extract. Valerenic acid and both valerian extracts interacted synergistically with clonazepam to extended the latency period to the onset of seizure. Phenytoin showed interaction only with the ethanolic valerian extracts.

Conclusions: Valerenic acid and valerian extracts have anticonvulsant properties in adult zebrafish. Valerian extracts markedly enhanced the anticonvulsant effect of both clonazepam and phenytoin, and could contribute to therapy of epileptic patients.
\end{abstract}

Keywords: Herbal-Drug Interaction, Antiepileptic drugs (AEDs), Phenytoin, Clonazepam, Clonic-like seizures, Pentylenetetrazole-induced seizures

\footnotetext{
* Correspondence: bianca.torreshernandez12@gmail.com

Neuropharmacology Laboratory, Pharmacology and Toxicology, Department University of Puerto Rico- Medical Science Campus, PO Box 365067, San Juan 00936-5067, Puerto Rico
} 


\section{Background}

Epilepsy is a neurological disease with different causes e.g. genetic, structural/metabolic and unknown reasons [1]. In 2012, the Word Health Organization estimate 50 million of people worldwide have epilepsy [2]. Treatment of epileptic patients is difficult because of the inability of current antiepileptic drugs (AEDs) to control some types of seizures in almost $30 \%$ of the patients [2-4]. Other problems associated with current AEDs include low patient compliance [5-7], cognitive problems induced by AEDs [8] and the development of drug resistance $[9,10]$ among others.

Patients often combine multiple drugs, including natural products, to obtain better seizure control [11], or to treat other health conditions [12, 13] (reviewed in [14]). Interactions of AEDs with other drugs including other anticonvulsants and natural products is a clinical problem [15-17]. Extracts of valerian roots have been used for more than 2000 years to treat a variety of symptoms, such as anxiety and insomnia [18], and for their anticonvulsant properties $[19,20]$ (reviewed in [21]). It has been documented that patients who self-administer valerian with AEDs may experience increased sedation [21, 22]. Nonetheless, few studies have rigorously examined the anticonvulsant properties of valerian extracts [23-25], and more evidence is required to determine if valerian extracts alter the therapeutic effects of AEDs. The principal objective of the present work was to determine whether valerenic acid or valerian extracts interact with well-studied traditional AEDs phenytoin and clonazepam, to potentiate or reduce their anticonvulsant effect.

Valeriana officinalis contains more than 150 chemical constituents identified in the essentials oils [26] and some constituents variation are found from plant harvest $[27,28]$. Valerenic acid is considered to be the principal constituent $[29,30]$. The aqueous extract contain hydroxylvalerenic acid and acetoxyvalerenic acid in varying proportions [31, 32]. The second objective of the work was to examine the anticonvulsant properties of valerenic acid alone, as well as the aqueous and ethanolic extracts of Valeriana officinalis. These studies were performed in adult zebrafish (Danio rerio), an animal model used to study clonic-like behaviors [33-36] and for screening drugs [37, 38].

\section{Methods}

\section{Animals and maintenance}

Adult male and female, wild-type short-fin zebrafish (Danio rerio), 3-6 months old and weighing $0.25 \pm$ $0.04 \mathrm{~g}$ (mean \pm SEM) were obtained from Caribe Fisheries Inc. (Lajas, Puerto Rico). Each purchase of 100-200 fish was termed a "batch". Zebrafish, approximately 1:1 female to male were maintained in an aquarium with an automatic filtration system and covered with blue contact paper to reduce stress. Fish were fed by an automatic feeder two times daily with Wardley Tropical Fish Premium Flakes Food. The animal room was illuminated on a 14/10 h light/dark cycle. Room temperature was maintained at $25^{\circ} \mathrm{C} \pm 1{ }^{\circ} \mathrm{C}$. The animals were observed in quarantine at least one week before use in experimental studies. This study was carried out in strict accordance with the recommendations in the Guide for the Care and Use of Laboratory Animals of the National Institutes of Health. The protocol was approved by the Institutional Animal Care and Use Committee of the University of Puerto Rico, Medical Sciences Campus (Protocol number 3180110). All efforts were made to minimize animal pain and suffering.

\section{Chemicals}

Valerenic acid (VA) was purchased from Chromadex (Irvine, CA.), clonazepam from Roche (Caguas, PR), and phenytoin from Parke-Davis Div of Pfizer Inc. Gabapentin, valproic acid sodium salt and pentylenetetrazole (PTZ) were obtained from Sigma-Aldrich Co. (St. Louis, MO).

The valerenic acid stock solution was prepared by dissolving valerenic acid powder in ethanol (70 \%); the stock solution was stored at $-20{ }^{\circ} \mathrm{C}$ for no more than two months. Dilutions were prepared with aquarium water. The ethanol concentration in valerenic acid solutions $(0.40$ to $89.5 \mathrm{~g} / \mathrm{ml})$ ranged from 0.0059 to $1.4 \%$, respectively.

Aqueous and ethanolic extracts were prepared from certified organically grown dry powdered roots (Lot $111 \mathrm{H}$-OUP; harvested in 2004) and from fresh valerian roots (Lot 1020P-OUF, harvested in 2008). Both were obtained from Pacific Botanicals (LLC Grants Pass, Oregon).

Extraction methods were modified from Del ValleMojica et al. [39]. For the ethanolic extract, dry valerian powder $(150 \mathrm{mg} / \mathrm{ml})$ was stirred in $70 \%$ ethanol in a covered beaker at room temperature $\left(25{ }^{\circ} \mathrm{C}\right)$ for $1 \mathrm{~h}$. Aqueous extracts were prepared from either fresh root or dry valerian powder $(100 \mathrm{mg} / \mathrm{ml})$. Fresh roots were first ground in a blender (Windmere Mod. BD70) at Liquefy mode with Milli-Q ultra-pure water for $2 \mathrm{~min}$. Aqueous preparations were extracted by stirring in a covered beaker for $1 \mathrm{~h}$ at room temperature. Particulates were removed by filtering through coarse filter paper (dry powder) or by centrifugation (fresh root) at $6700 \mathrm{~g}$. Extracts were prepared fresh daily for each experiment and were not stored.

\section{Composition of valerian extracts}

Both aqueous and ethanolic valerian extracts of dry valerian powder (Lot $111 \mathrm{H}$-OUP) were prepared and analyzed by Chromadex, Inc. (Irvine, CA) to detect and 
quantify valerenic acid species (hydroxyvalerenic, acetoxyvalerenic, and valerenic acid) using high-performance liquid chromatography (HPLC). In summary $1250 \mathrm{mg}$ of valerian powder roots were extracted with Milli-Q water or $70 \%$ ethanol in a $25 \mathrm{ml}$ flask and stirred $1 \mathrm{~h}$ at room temperature. The extract was then filtered using a $12.5 \mathrm{~cm}$ Whatman qualitative \#1 filter followed by a $10 \mathrm{~min}$ centrifugation at $3700 \mathrm{rpm}$. The sample was filtered through a $0.45 \mu \mathrm{m}$ PTFE into an HPLC vial for analysis. Agilent 1100 Series HPLC system was used, with Phenomenex Kinetex C18 $30 \times 2.1 \mathrm{~mm}, 2.6 \mu \mathrm{m}$ column at $50{ }^{\circ} \mathrm{C}$. Elution was done with two mobile phase $0.1 \%$ phosphoric acid and acetonitrile. The injection volume was $0.8 \mu \mathrm{l}$ with a flow rate of $0.5 \mathrm{ml} / \mathrm{min}$. Detection was done with UV/Vis at $210 \mathrm{~nm}$.

\section{PTZ experiments}

All experiments were performed with randomly selected, untreated male and female zebrafish. Experiments were started between 8:00 am and 4:00 pm. Experiments were performed with 12-16 animals per point, a number which previously provided statistically valid results in adult zebrafish [40].

\section{PTZ-induced seizures (convulsion) progression scale}

The scale was developed with naïve (untreated) zebrafish (2-4 per group, 12-16 fish per concentration). Fish were immersed in a clear plastic tank, $(7.5 \mathrm{~cm} \times 4.5 \mathrm{~cm} \times$ $6.0 \mathrm{~cm})$ containing PTZ $(0.1-20 \mathrm{mg} / \mathrm{ml})$ in a final volume of $100 \mathrm{ml}$ aquarium water. Behavior was recorded with a Panasonic SD Video Camera, Model \# SDR- S26, for a maximum of $30 \mathrm{~min}$. The video was observed to score the convulsion stages.

\section{Pretreatments}

Prior to the PTZ exposure, naïve zebrafish (3-4 per group) were pretreated by immersion (to minimize stress to animals) for $1 \mathrm{~h}$ in a $15 \mathrm{ml}$ chamber $(3.0 \mathrm{~cm} \times 5.0 \mathrm{~cm} \times$ $2.5 \mathrm{~cm}$ ) containing treatment (valerenic acid, valerian extracts or AEDs) dissolved in aquarium water (Additional file 1). Animals were monitored continuously during the pretreatment period. Because of the toxicity of valerenic acid, pretreatment was for a maximum of $5 \mathrm{~min}$. Possible interactions between AEDs (phenytoin and clonazepam) and valerian extracts were tested with the same protocol, except that the pretreatment tank contained combinations of phenytoin $(1 \mathrm{mg} / \mathrm{ml})$ or clonazepam $(0.5 \mu \mathrm{g} / \mathrm{ml})$ with valerian extracts. For valerenic acid combinations with phenytoin or clonazepam, fish were first pretreated for $1 \mathrm{~h}$ in water containing the AED, then transferred to a tank containing only valerenic acid $(37 \mu \mathrm{g} / \mathrm{ml})$ for $5 \mathrm{~min}$. Preliminary experiments with a range of concentrations of valerenic acid and valerian extracts were performed to determine the appropriate range for the concentration- response curve. Concentrations higher than $0.1 \mathrm{mg} / \mathrm{ml}$ valerenic acid, $2 \mathrm{mg} / \mathrm{ml}$ ethanolic valerian extract or $25 \mathrm{mg} / \mathrm{ml}$ aqueous valerian extract were not tested due to toxicity (e.g., fish lost posture, lay on its side, had no mobility with exception of the gills (a sign of sedation) or died during the absorption time).

\section{Latency experiments}

Following pretreatment, fish were transferred to a clear plastic tank, $(7.5 \mathrm{~cm} \times 4.5 \mathrm{~cm} \times 6.0 \mathrm{~cm})$ containing PTZ $(3 \mathrm{mg} / \mathrm{ml})$ in a final volume of $100 \mathrm{ml}$ aquarium water. Behavior was continuously monitored and recorded with a Panasonic SD Video Camera, Model \# SDR-S26 for 10 min or until the zebrafish lost posture (maximum of $30 \mathrm{~min}$ ). The seizure latency period was defined as the time from initial exposure to PTZ until zebrafish reached Stage 7 (defined as a wild jump, clonic-like movement (convulsion), immediately followed by the loss of posture). After the convulsion, animals were removed to the washout tank.

If animals did not show both clonic movements and loss of posture, they were considered to be seizure-free and were not included in the data analysis. The video was observed to score the convulsion stages and to quantify the latency of each fish. Each set of experiments was repeated at least three times using animals from different batches and a minimum of 6 zebrafish per data point. All studies included animals with no pretreatment exposed to PTZ, as daily controls, in addition to animals pretreated with test drugs. The concentrations of AEDs used in drug combination experiments were based on our preliminary concentration-response studies in adult zebrafish.

\section{Statistical analysis}

Analysis of variance (ANOVA) and $\mathrm{IC}_{50} / \mathrm{EC}_{50}$ analyses were calculated with GraphPad Prism software (La Jolla, CA). Latency data are presented as mean \pm standard error of the mean (SEM) for individual animals. One-way ANOVA followed by Tukey post-hoc test was performed, using a $p<0.05$ level of significance. All treatments were compared with the untreated controls and with the other pretreatments.

\section{Results}

\section{Seizure progression in adult zebrafish}

Zebrafish exposed to PTZ exhibited a sequence of behaviors before the clonic-like movements (wild jumping) followed by loss of posture that characterized the PTZinduced seizure. We defined "loss of posture" as the state when the zebrafish lay on its side or had an involuntary vertical position (Fig. 1). The appearance of progressive stages was concentration-dependent (Table 1). In Stage 1 animals usually went to the bottom of the 


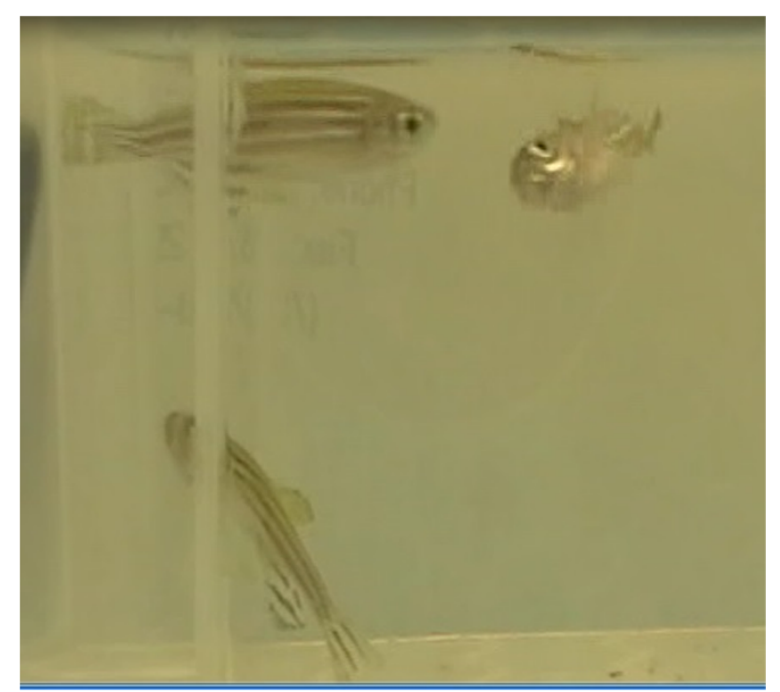

Fig. 1 Representative photo of zebrafish after exposure to PTZ $3 \mathrm{mg} / \mathrm{ml}$. Top left, normal posture; top right, laying on its side (Stage 7); bottom, animal with vertical position

tank either did not move or moved only very close to the bottom. After a few seconds, they began to move very rapidly (Stage 2). In Stage 2, the animals increased their locomotion during $10 \mathrm{~min}$ of exposure to PTZ. With PTZ concentrations below $0.5 \mathrm{mg} / \mathrm{ml}$, animals did not progress to other stages of our scale during the 30 min observation period. The complete sequence of behavioral stages 2-7 observed with PTZ concentrations of $0.5 \mathrm{mg} / \mathrm{ml}$ and higher included the following: Increased locomotion (Stage 2); hit the tank walls (Stage 3); go to the water surface and then rapidly to the bottom of the tank (Stage 4); faster, occasional shaking movement (Stage 5); and erratic circular or diagonal movement
(Stage 6). Stage 7 was characterized as wild jump, cloniclike movement (convulsion), and loss of coordination/posture, staying at the bottom and later recovering posture and motion. This stage could be identified from 0.7 to $3 \mathrm{mg} / \mathrm{ml}$ (5-22 $\mathrm{mM})$ PTZ. The progression between stages at higher PTZ concentrations $(6-20 \mathrm{mg} / \mathrm{ml} ; 43-$ $144 \mathrm{mM})$, was very fast, and we could only identify the more obvious stages $(1,2,6,7$, and 9). Stage 7 was the most clearly reproducible behavior regardless of the pharmacological pretreatment, and for that reason was selected as the end point for quantifying latency. If an animal did not present stage 7 , it was considered a seizurefree animal.

\section{The PTZ latency concentration-response curve}

The seizure latency to the Stage 7 , clonic-like movement was determined by exposing zebrafish to a range of PTZ concentrations from 0.7 to $20 \mathrm{mg} / \mathrm{ml}$ for $10 \mathrm{~min}$ (Fig. 2). Zebrafish did not lose posture during the 10-min exposure to PTZ with concentrations below $0.80 \mathrm{mg} / \mathrm{ml}$. With increasing PTZ concentration $(0.70$ to $5 \mathrm{mg} / \mathrm{ml}$ ), the latency to the onset of convulsions decreased in a concentration-dependent fashion. The $\mathrm{EC}_{50}$ for PTZ-induced convulsions in adult zebrafish was $0.49 \mathrm{mg} / \mathrm{ml}$ (95\% Confidence Interval, 0.43$0.56 \mathrm{mg} / \mathrm{ml})$.

\section{The effect of traditional AEDs on the latency to convulsion compared with ethanolic valerian extract}

Naïve (untreated) animals had a seizure latency of $107 \pm$ 8 sec after PTZ challenge (Fig. 3). Traditional AEDs significantly increased the seizure latency after $1 \mathrm{~h}$ of pretreatment: gabapentin $(1 \mathrm{mg} / \mathrm{ml}), 309 \pm 18 \mathrm{sec}$ and valproate $(1 \mathrm{mg} / \mathrm{ml}), 298 \pm 19 \mathrm{sec}(p<0.0001)$; phenytoin (2 $\mathrm{mg} / \mathrm{ml}), \quad 192 \pm 26$ sec $(p<0.001)$. The ethanolic

Table 1 Progression toward clonic-like movement with PTZ in adult zebrafish

\begin{tabular}{|c|c|c|}
\hline Stage & Stage description & $\begin{array}{l}\text { PTZ Concentration at which } \\
\text { the behavior is first seen }\end{array}$ \\
\hline 1 & Stay or move near the bottom of the tank & $0.10 \mathrm{mg} / \mathrm{ml}(0.72 \mathrm{mM})$ \\
\hline 2 & Rapid movement in all directions, & $0.10 \mathrm{mg} / \mathrm{ml}(0.72 \mathrm{mM})$ \\
\hline 3 & Hit the tank walls & $0.50 \mathrm{mg} / \mathrm{ml}(3.6 \mathrm{mM})$ \\
\hline 4 & Rapidly go to the water surface and then rapidly go to the bottom of the tank & $0.70 \mathrm{mg} / \mathrm{ml}(5.0 \mathrm{mM})$ \\
\hline 5 & Shaking movement & a \\
\hline 6 & Erratic movements (circular motion, diagonal movement) & $0.70 \mathrm{mg} / \mathrm{ml}(5.0 \mathrm{mM})$ \\
\hline 7 & Wild jumping, Clonic-like movement (convulsion) then loss of coordination/ posture, remaining at the bottom & $0.70 \mathrm{mg} / \mathrm{ml}(5.0 \mathrm{mM})$ \\
\hline 8 & Recover posture/motion & $0.70 \mathrm{mg} / \mathrm{ml}(5.0 \mathrm{mM})$ \\
\hline 9 & Death & $1 \mathrm{mg} / \mathrm{ml}^{\mathrm{b}}(7.5 \mathrm{mM})$ \\
\hline
\end{tabular}

Zebrafish ( $n=6-12$ per concentration) were exposed to different concentrations of pentylenetetrazole (PTZ) for 30 min. The development of convulsions was analyzed by observation of video tapes. At higher concentrations $(6-20 \mathrm{mg} / \mathrm{ml})$ some pre-convulsion stages were not observed

${ }^{\mathrm{a}}$ Few naive zebrafish presented this stage, but it was observed in zebrafish challenged with PTZ ( $\left.3 \mathrm{mg} / \mathrm{ml}, 21.7 \mathrm{mM}\right)$ after pretreatment with AEDs or valerians

${ }^{b}$ Some animals survived after $30 \mathrm{~min}$ 


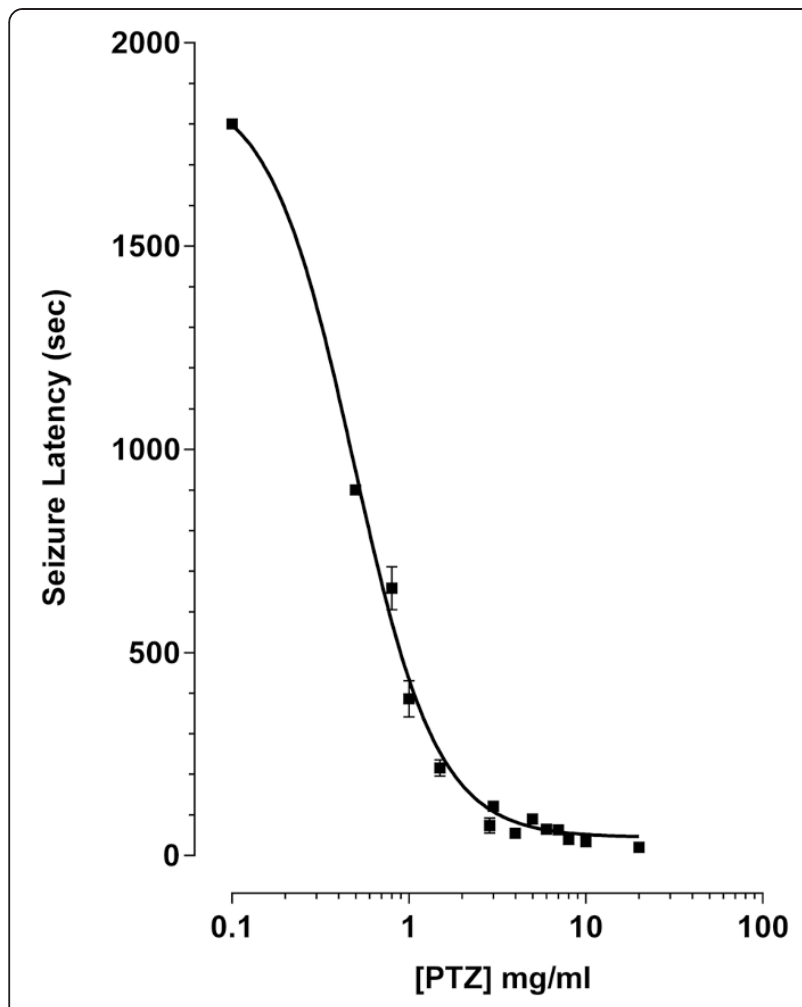

Fig. 2 PTZ concentration-response. The latency to Stage 7 PTZ-evoked convulsions was determined in adult zebrafish. Naïve zebrafish $(n=6-12)$ were placed in the convulsion chamber containing PTZ $(0.5-20 \mathrm{mg} / \mathrm{ml}$; 0.7-145 mM). The seizure latency period was defined as the time from initial exposure to PTZ until the beginning of Stage 7 (wild jumping immediately followed by loss of posture). The $\mathrm{EC}_{50}$ for PTZ-evoked convulsions was 0.49 mg/ml (95 \% Confidence Interval, 0.43 to $0.56 \mathrm{mg} / \mathrm{ml})$. Data are mean \pm SEM

valerian extract $(1 \mathrm{mg} / \mathrm{ml})$ increased the latency to $375 \pm$ $32 \mathrm{sec}$, significantly greater than all other treatments compare with naïve fish $(p<0.0001)$. Diluted ethanol $(0.47 \%)$, the solvent for the ethanolic valerian extract, did not show significant anticonvulsant properties.

\section{Concentration-response curves of valerenic acid and valerian extracts}

The concentration dependency of the ability to delay the latency to convulsion was determined for valerenic acid and the two valerian extracts (Fig. 4). Zebrafish were pretreated for only three minutes with valerenic acid. Concentrations of $18.5 \mu \mathrm{g} / \mathrm{ml}$ and higher (ethanol 0.0059-1.4\%) significantly prolonged the latency to convulsion $(p<0.001)$. Valerenic acid (VA) exhibited toxicity at $89.5 \mu \mathrm{g} / \mathrm{ml}$ and above, with fish exposed for longer than three minutes losing posture in the absorption chamber. The ethanolic valerian extract $\left(\mathrm{Val}_{\mathrm{E}}\right)$ was more potent than the aqueous extract $\left(\mathrm{Val}_{\mathrm{A}}\right)$, and significantly increased the seizure latency at concentrations $0.50 \mathrm{mg} / \mathrm{ml}$ and higher (ethanol $0.23-0.93 \%$ ). These ethanol concentrations had no significant anticonvulsant properties (data not shown). The aqueous valerian extract also significantly increased the latency to convulsions at $5 \mathrm{mg} / \mathrm{ml}$ or higher $(p<0.05)$. Aqueous extracts prepared from two separate harvests (2004 and 2008) had indistinguishable anticonvulsant effects on latency to PTZ challenge (Additional file 2).

\section{Interactions of valerenic acid and valerian extracts with AEDs}

The possibility that valerenic acid or the extracts (ethanolic or aqueous) could interact either positively or negatively with AEDs was tested by pretreating fish with drug mixtures containing AEDs and extracts prior to PTZ challenge (Fig. 5). Minimally effective concentrations of valerenic acid $(37 \mu \mathrm{g} / \mathrm{ml})$ and valerian extracts (ethanolic extract, $0.5 \mathrm{mg} / \mathrm{ml}$; aqueous extract, $5 \mathrm{mg} / \mathrm{ml}$ ) were identified from the concentration-response study (unbroken horizontal line in Fig. 4) and were combined with a sub-therapeutic concentration of phenytoin $(1 \mathrm{mg} / \mathrm{ml})$. The latency to convulsion in zebrafish treated only with phenytoin was not significantly different from

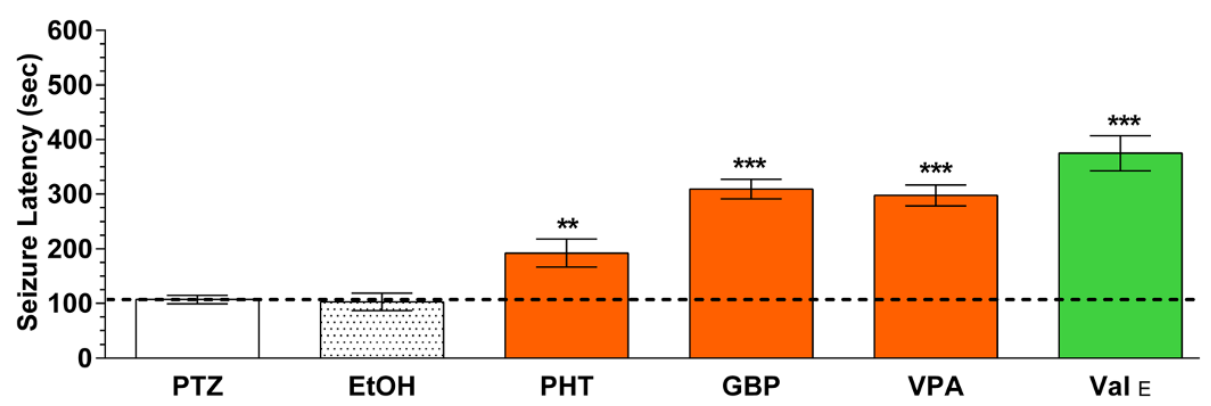

Fig. 3 Latency to Stage 7, convulsion-like behavior with antiepileptic drugs (AEDs) and the ethanolic valerian extract. Zebrafish were exposed for $1 \mathrm{~h}$ to gabapentin (GBP, $1 \mathrm{mg} / \mathrm{ml} ; 5.8 \mathrm{mM}$ ), valproate (VPA, $1 \mathrm{mg} / \mathrm{ml} ; 6 \mathrm{mM})$, phenytoin (PHT, $2 \mathrm{mg} / \mathrm{ml} ; 7.9 \mathrm{mM})$, or the ethanolic valerian extract (Val 1 , $\mathrm{mg} / \mathrm{ml}$ ). All AEDs significantly increased the latency period to Stage 7 PTZ-induced convulsions (PTZ, 3 mg/ml) when compared with untreated zebrafish. Similarly, the ethanolic valerian extract also increased the latency. Ethanol (EtOH) present in the ethanolic valerian extract (0.47 \%) had no effect. Data are mean \pm SEM of experiments with 9-12 fish per treatment. Inter-group comparisons were by ANOVA. ${ }^{* *} p<0.001$ or ${ }^{* *} p<0.0001$ vs PTZ 


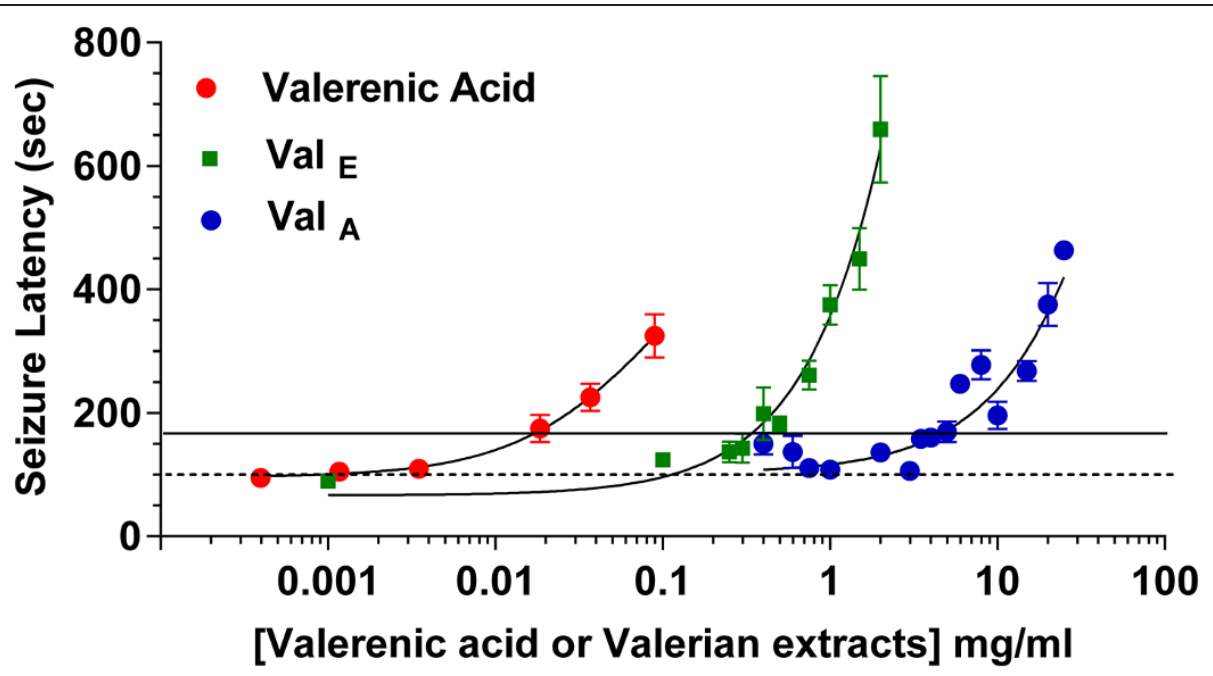

Fig. 4 Concentration-response curves of valerenic acid, ethanolic and aqueous valerian extract. Zebrafish ( $n=12-20$ fish per concentration) were exposed to valerenic acid $(V A)$, ethanolic $\left(\left.V_{a}\right|_{E}\right)$ or aqueous $\left(\left.V_{a}\right|_{A}\right)$ valerian extracts followed by PTZ challenge. The dashed line represents the seizure latency in untreated fish. All values above the solid horizontal line are significantly different from untreated animals, $p<0.001$ or $p<0.0001$. (Statistics were omitted for clarity). The threshold concentrations for significant increases in latency were $18.5 \mu \mathrm{g} / \mathrm{ml}$ for valerenic acid, $0.5 \mathrm{mg} / \mathrm{ml}$ for the ethanolic valerian extract, and $5 \mathrm{mg} / \mathrm{ml}$ for the aqueous valerian extract
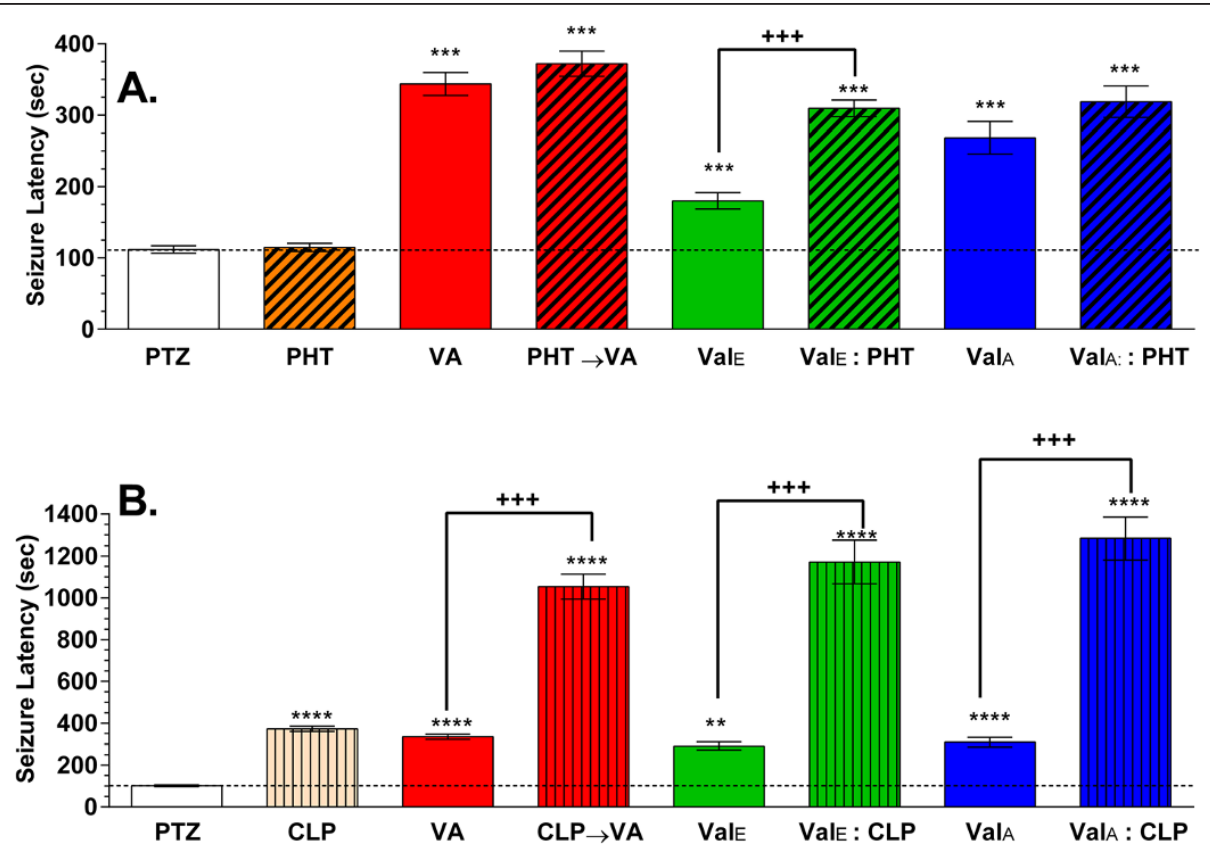

Fig. 5 Interaction of valerian extracts or valerenic acid with phenytoin (PHT) or clonazepam (CLP). After $1 \mathrm{~h}$ of pretreatment and subsequent exposure to PTZ (3 mg/ml, $21.7 \mathrm{mM})$. a PHT (1 mg/ml, $3.9 \mathrm{mM}$ ) had no anticonvulsant effect in zebrafish. However, valerenic acid (VA, $37 \mu \mathrm{g} / \mathrm{ml})$, ethanolic valerian extracts $\left(\mathrm{Val}_{\mathrm{E}}, 0.5 \mathrm{mg} / \mathrm{ml}\right)$, and aqueous valerian extracts $\left(\mathrm{Val}_{\mathrm{A}}, 5 \mathrm{mg} / \mathrm{ml}\right)$ and the co-administration of $\mathrm{Val}_{\mathrm{E}}$ and PHT significantly increased the latency. In contrast, there was no further increase in latency when PHT was co-administered with Val $\mathrm{A}_{\mathrm{A}}$ or before VA. $\mathbf{b}$ All treatments increased significantly the latency in comparison to untreated fish (PTZ). The combination of clonazepam $(5 \mu \mathrm{g} / \mathrm{ml} ; 0.02 \mathrm{mM})$ with valerenic acid $(37 \mathrm{\mu g} / \mathrm{ml})$, ethanolic valerian extract $(1 \mathrm{mg} / \mathrm{ml})$ or aqueous valerian extract $(5 \mathrm{mg} / \mathrm{ml})$ increased the anticonvulsant properties of the individual treatments $(p<0.001)$. The dashed line represents the seizure latency in untreated fish. Data are mean \pm SEM from three experiments with $8-21$ fish for each treatment, ${ }^{* *} p<0.01$ or ${ }^{* *} p<0.001$ or ${ }^{* * *} p<0.0001$ vs untreated; $+++p<0.001$ vs treatments alone and PTZ 
untreated, naïve fish, $112 \pm 5$ sec. After pretreatment with the ethanolic valerian extract, the latency was $180 \pm$ $12 \mathrm{sec}$. Pretreatment with the mixture of sub-therapeutic phenytoin and the ethanolic valerian extract $\left(\mathrm{Val}_{\mathrm{E}}: \mathrm{PHT}\right)$ significantly increased the latency to PTZ challenge to $310 \pm 12 \mathrm{sec}$, around three times that latency of naïve fish, and significantly different from the latency in the ethanolic extract alone $(p<0.0001)$. In contrast, when the aqueous valerian extract was co-administered with phenytoin $\left(\mathrm{Val}_{\mathrm{A}}: \mathrm{PHT}\right)$, the latency was not significantly different from those pretreated with the aqueous extract alone. Because of the toxicity of valerenic acid in adult zebrafish, fish were first exposed to phenytoin and then to valerenic acid $(37 \mu \mathrm{g} / \mathrm{ml})$ for five minutes $(\mathrm{PHT} \rightarrow \mathrm{VA})$, also failed to show a significant increase in latency compared with fish pretreated with valerenic acid alone $(372 \pm 18$ vs $344 \pm 16 \mathrm{sec}$, respectively).

In contrast with the modest interaction with phenytoin, valerenic acid and valerian extracts strongly potentiated the anticonvulsant effect of clonazepam $(5 \mu \mathrm{g} / \mathrm{ml})$ (Fig. 5b). Zebrafish pretreated with clonazepam and then with valerenic acid (CLP $\rightarrow$ VA) significantly increased the latency to $1054 \pm 59 \mathrm{sec}$, compared with $335 \pm 12 \mathrm{sec}$ in those pretreated with valerenic acid alone. The ethanolic valerian extract $(1 \mathrm{mg} / \mathrm{ml})$ combined with clonazepam significantly $\left(\mathrm{Val}_{\mathrm{E}}\right.$ : CLP) increased the latency to $1172 \pm 104$ sec compared with $291 \pm 19$ sec in fish pretreated with the ethanolic valerian extract alone, or $373 \pm$ $13 \mathrm{sec}$ in fish pretreated with clonazepam alone, and $102 \pm 4 \mathrm{sec}$ in untreated naïve animals. The aqueous valerian extract $(5 \mathrm{mg} / \mathrm{ml})$ combined with clonazepam $\left(\mathrm{Val}_{\mathrm{A}}: \mathrm{CLP}\right)$ also significantly increased the latency to $1284 \pm 102 \mathrm{sec}$, compared with $309 \pm 23 \mathrm{sec}$ for those pretreated with the aqueous extract alone. All combinations of clonazepam with valerenic acid or valerian extracts significantly $(p<0.0001)$ potentiated the latency compared to pretreatments with each drug individually. Remarkably, nearly half of the fish (7/16) treated with the mixture of clonazepam and the aqueous valerian extracts did not present clonic-like movement followed by loss of posture during the $30 \mathrm{~min}$ observation period. They had normal or fast swimming behavior, and were recorded as seizure-free. All the animals treated with clonazepam plus valerian mixtures survived the half hour exposure to $3 \mathrm{mg} / \mathrm{ml} \mathrm{PTZ,} \mathrm{com-}$ pared with untreated animals, which only $35 \%$ survived (unpublished data from our lab).

\section{HPLC analysis of aqueous and ethanolic valerian extracts}

Valerenic acid was not detected in the aqueous valerian extract above the reporting limit $(0.0051 \mathrm{mg} / \mathrm{g}$ of root) and the concentration of acetoxyvalerenic $(0.090 \mathrm{mg} / \mathrm{g})$ was lower than in the ethanolic extract $(0.796 \mathrm{mg} / \mathrm{g})$. However the amount of hydroxyvalerenic acid was similar in both extracts, $0.193 \mathrm{mg} / \mathrm{g}$ vs $0.206 \mathrm{mg} / \mathrm{g}$ in the ethanolic and aqueous extracts, respectively.

\section{Discussion}

The zebrafish is an excellent animal model to study behavior and neurological diseases [41-43] including clonic-like behaviors [35, 36], and for screening potential anti-epileptic drugs [37]. We demonstrated that valerenic acid and valerian extracts potentiate the antiepileptic activity of both commercial anticonvulsants phenytoin and clonazepam in adult zebrafish. The progression to PTZ-induced convulsions that we observed in adult zebrafish is very similar to that recently described by Mussulini et al. [33].

To our knowledge, there is no research demonstrating a possible beneficial interaction of valerian extract with antiepileptic drugs. We selected phenytoin and clonazepam, drugs from the first generation AEDs, because they still play an important role in the treatment of clonic convulsions $[44,45]$. In the future valproate, gabapentin, and other AEDs should be tested. The positive interaction of ethanolic valerian extracts with phenytoin suggests that adequate concentrations of the ethanolic extract could enhance the effects of sub-therapeutic concentrations of phenytoin. Neither the aqueous valerian extracts nor valerenic acid interact with phenytoin. On the other hand, valerenic acid and both valerian extracts exhibited strong synergism with clonazepam. The mixture of valerians with clonazepam also reduced the risk of mortality in the zebrafish. This suggests that a clonazepam-valerian mixture could be neuroprotective.

In our experiments, the ethanol concentration used as a solvent for the alcoholic valerian extracts and valerenic acid did not have anticonvulsant properties. The final concentration of ethanol in the valerenic acid solution-that did not interact with phenytoin-was the same as the ethanol concentration in the valerian extracts that did interact positively. We do not know if a possible interaction of ethanol with some constituent of the extract are responsible of the observed synergism. Also, we cannot discard the possibility that ethanol could have an effect at higher concentrations in zebrafish or in other animal models. Ethanol reduced the duration of seizure induced by PTZ in mice and enhance the anticonvulsant properties of valproic acid [46].

From the experiments performed, we cannot determine if the interactions between AEDs and extracts were pharmacokinetic, pharmacodynamic or both. Phenytoin in humans is metabolized principally by CYP2C9 and 2C19 [47-49], and clonazepam is metabolized by CYP3A and other P450 cytochrome enzymes [50]. Healthy volunteers have little direct effect on the enzymatic activity of CYP3A4 and CYP2D6 using valerian [51]. Studies in vitro with cultured human hepatocytes 
exposed to common valerian $(187.5 \mu \mathrm{g} / \mathrm{ml}$ or $1875 \mu \mathrm{g} / \mathrm{ml})$ reported induction of CYP2D6 and CYP3A4 but not CYP1A2 [52]. At lower concentrations, weaker induction of CYP2C19 and weaker inhibition of CYP2E1 was reported [53]. Therefore, we think it is likely that pharmacodynamic interactions would better explain our results.

The compounds responsible for the anticonvulsant properties of valerian have not been identified, although many compounds have been identified in valerian extracts, including valepotriates, alkaloids, sesquiterpenes, alcohols, volatile oils, aromatic compounds and other polar and non-polar organic compounds $[26,54]$. The medicinal properties of valerian extracts is attributed to valerenic acid, one of the main components in valerian extracts [30]. The HPLC analysis of valerian species present in our extracts found valerenic acid to be present in the ethanolic extract, in addition to hydroxyvalerenic acid and acetoxyvalerenic acid, but valerenic acid was not detected in the aqueous extract although both hydroxyvalerenic acid and acetoxyvalerenic acid were also present. Our data clearly show that pure valerenic acid has strong anticonvulsant properties, but both valerian extracts also have significant anticonvulsant activity. Moreover, the aqueous valerian extract, which did not contain valerenic acid, potentiated the effect of clonazepam more effectively than valerenic acid (Fig. 5b). Thus, valerenic acid is not solely responsible for the anticonvulsant properties of valerian. It is unlikely that hydroxyvalerenic acid is the responsible component, since its concentration is roughly the same in both the aqueous and ethanolic extracts. It is possible that other compounds present in the extracts, or the interaction of various compounds are mainly responsible for the effectiveness of valerian extracts to delay the onset of seizure in fish. Two valerian species that do not contain valerenic acid, $V$. edulis and $V$. pavoniis, also have anticonvulsant properties [55-57].

This work required the development of a PTZ Convulsion Progression Scale for adult zebrafish. The progression toward convulsions was similar to that evoked by injecting adult zebrafish with kainate, an ionotropic glutamate agonist [58]. Our scale is quite similar to a recently published scale for adult zebrafish using a limited range of PTZ concentrations, 5-15 mM [33], whereas we examined concentrations up to $144 \mathrm{mM}$ PTZ. There were several small differences in the behaviors reported. For examples, prior to the erratic movement at Stage 6 we clearly identified two stereotypical behaviors not previously reported, i.e., animals hit the tanks walls (Stage 3) and traveled from the bottom to the surface faster (Stage 4). We also noted that animals could recover posture and motion before death at concentrations of PTZ under $30 \mathrm{mM}$. We also observed that PTZ was not pro-convulsive at concentrations below $5.8 \mathrm{mM}$ in the first $10 \mathrm{~min}$, but promoted increased locomotor activity, as has been previously reported [59]. Under our conditions, animals did not pass through all PTZ stages after some pretreatments, especially with higher concentrations. Therefore, we decided to use Stage 7 as the end-point to quantify the latency in all experiments.

The only way to assure that the animal have or not a seizure is with an electroencephalography recorded. A limitation in our study was the absence of the activity records and for these reason we named the fish behavior as clonic-like convulsion. If sedation is induced by the treatments, it could delay or masked the clonic-like convulsion. To minimize this possibility we assure that the animal had normal swimming or fast swimming pattern toward the clonic-like movement, whereas sedated animal usually did not move or had slow movement. We observed sedation in those fish treated with higher doses of the valerenic acid, valerian extracts or clonazepam but sedation was not observed at the doses used to determine if the interaction occurs between the treatments.

Our results demonstrated that adult zebrafish can tolerate higher concentrations of both PTZ and AEDs than previously reported for either larval zebrafish [38] or for adult zebrafish [33, 35, 60, 61]. The age-dependent differences in drug response may be attributable to differences in body mass and metabolic capabilities, as has been observed in juvenile and adult rats [62], and humans [63].

\section{Conclusion}

We demonstrate that PTZ challenge in adult zebrafish is a good animal model to study potential antiepileptic drugs. Valerenic acid and Valeriana officinalis (both aqueous and ethanolic extracts) increase the latency to PTZ-induced seizure in adult zebrafish in a concentration-dependent manner, with the ethanolic extract being more potent. Ethanolic valerian extracts strongly potentiate the antiepileptic effects of both phenytoin and clonazepam. All valerian preparations and valerenic acid interacted synergistically with a minimally effective concentration of clonazepam to strongly increase the latency to convulsions and improve survival. These results suggest possible new therapeutic alternatives for epileptic patients.

\section{Additional files}

Additional file 1: Methodology Representative Schematic. Show the animals in the absorption chamber and Latency Challenge.

Additional file 2: Dose-response Curve aqueous extract Valerian harvest $\mathbf{2 0 0 4}$ and 2008. The graph show seizure latency of animals pretreated with selected dose of extract prepared with different harvest roots (2004 and 2008).

\section{Abbreviations}

AEDs: Antiepileptic drugs; CLP: Clonazepam; PHT: Phenytoin; PTZ: Pentylenetetrazole; VA: Valerenic acid; Val $\left.\right|_{E}$ : Ethanolic Valerian extract; $\mathrm{Val}_{\mathrm{A}}$ : Aqueous Valerian extract; CYP: Cytochrome P450. 


\section{Competing interests}

Part of this work was presented on $23^{\text {rd }}$ Biennial Meeting ISN-ESN 2011; Athens, Greece on August 2011 by Bianca A. Torres-Hernández.

The other authors have declared that no competing interests exist.

\section{Authors' contributions}

BTH conceived, designed and performed the experiments, collected and analyzed the data, and wrote the manuscript; LDV designed and participated in the concentration-response experiments for valerenic acid; JGO participated in the experiments design, helped in the data analysis and in the drafting of the manuscript. All authors read and approved the final manuscript.

\section{Acknowledgements}

The authors thank Dr. Philip Specht for comments and recommendations during the preparation of this article and Dr. Susan Corey for editorial assistance. Infrastructure support was provided in part by grants from the Research Centers for Minority Institution (RCMI/NIH Grant no. G12 MD007600). Lisa Del Valle-Mojica and Bianca A. Torres-Hernández received fund from the Institutional Minority Biomedical Research Support (MBRS-RISE) Program at the UPR-MSC (Grant: No. 2 R25 GM061838). The funders had no role in study design, data collection and analysis, decision to publish, or preparation of the manuscript. This research project is in partial fulfilment of the doctoral dissertation of Bianca A. Torres-Hernández.

\section{Received: 7 October 2014 Accepted: 18 June 2015}

Published online: 14 July 2015

\section{References}

1. Berg AT, Berkovic SF, Brodie MJ, Buchhalter J, Cross JH, van Emde Boas W, et al. Revised terminology and concepts for organization of seizures and epilepsies: report of the ILAE Commission on Classification and Terminology, 2005-2009. Epilepsia. 2010;51:676-85.

2. Epilepsy. [http://www.who.int/mediacentre/factsheets/fs999/en/\#]

3. Schmidt D. Drug treatment of epilepsy: options and limitations. Epilepsy Behav. 2009:15:56-65.

4. Kwan P, Brodie MJ. Early identification of refractory epilepsy. N Engl J Med. 2000:342:314-9.

5. Cramer JA, Glassman M, Rienzi V. The relationship between poor medication compliance and seizures. Epilepsy Behav. 2002;3:338-42

6. Chen H-F, Tsai Y-F, Lin Y-P, Shih M-S, Chen J-C. The relationships among medicine symptom distress, self-efficacy, patient-provider relationship, and medication compliance in patients with epilepsy. Epilepsy Behav. 2010;19:43-9.

7. Enríquez-Cáceres M, Soto-Santillana M. Non-compliance with pharmacological treatment in patients with epilepsy. Rev Neurol. 2006;42:647-54.

8. Hessen E, Lossius MI, Reinvang I, Gjerstad L. Influence of major antiepileptic drugs on attention, reaction time, and speed of information processing: results from a randomized, double-blind, placebo-controlled withdrawal study of seizure-free epilepsy patients receiving monotherapy. Epilepsia. 2006:47:2038-45.

9. Luna-Tortós C, Fedrowitz M, Löscher W. Evaluation of transport of common antiepileptic drugs by human multidrug resistance-associated proteins (MRP1, 2 and 5) that are overexpressed in pharmacoresistant epilepsy. Neuropharmacology. 2010;58:1019-32.

10. Lazarowski A, Lubieniecki F, Camarero S, Pomata H, Bartuluchi M, Sevlever G, et al. Multidrug resistance proteins in tuberous sclerosis and refractory epilepsy. Pediatr Neurol. 2004;30:102-6.

11. McConnell BV, Applegate M, Keniston A, Kluger B, Maa EH. Use of complementary and alternative medicine in an urban county hospital epilepsy clinic. Epilepsy Behav. 2014;34:73-6.

12. Metcalfe A, Williams J, McChesney J, Patten SB, Jetté N. Use of complementary and alternative medicine by those with a chronic disease and the general population-results of a national population based survey. BMC Complement Altern Med. 2010;10:58.

13. Barnes PM, Bloom B, Nahin RL. Complementary and alternative medicine use among adults and children: United States. Natl Health Stat Report. 2007;2008:1-23.

14. Fasinu PS, Bouic PJ, Rosenkranz B. An overview of the evidence and mechanisms of herb-drug interactions. Front Pharmacol. 2012;3:69.
15. Lucas RA, Gilfillan DJ, Bergstrom RF. A pharmacokinetic interaction between carbamazepine and olanzapine: observations on possible mechanism. Eur J Clin Pharmacol. 1998:54:639-43.

16. Landmark Johannessen C, Patsalos PN. Interactions between antiepileptic drugs and herbal medicines. Boletín Latinoam y del Caribe Plantas Med y Aromáticas. 2008;7:108-18.

17. Kupiec T, Raj V. Fatal seizures due to potential herb-drug interactions with Ginkgo biloba. J Anal Toxicol. 2005;29:755-8.

18. Monograph. Monograph. Valeriana officinalis. Altern Med Rev. 2004;9:438-41.

19. Eadie MJ. Could valerian have been the first anticonvulsant? Epilepsia. 2004;45:1338-43.

20. Tagarelli G, Tagarelli A, Liguori M, Piro A. Treating epilepsy in Italy between XIX and XX century. J Ethnopharmacol. 2013;145:608-13.

21. Spinella M. Herbal medicines and epilepsy: the potential for benefit and adverse effects. Epilepsy Behav. 2001;2:524-32.

22. Miller LG. Herbal medicinals: selected clinical considerations focusing on known or potential drug-herb interactions. Arch Intern Med. 1998;158:2200-11.

23. Khayat Nouri MH, Abbas Abad AN. Gabaergic system role in aqueous extract of Valeriana officinalis L. root on PTZ-induced clonic seizure threshold in mice. African J Pharm Pharmacol. 2011;5:1212-7.

24. Rezvani ME, Roohbakhsh A, Allahtavakoli M, Shamsizadeh A. Anticonvulsant effect of aqueous extract of Valeriana officinalis in amygdala-kindled rats: possible involvement of adenosine. J Ethnopharmacol. 2010;127:313-8.

25. Hiller K-O, Zetler G. Neuropharmacological studies on ethanol extracts of valeriana officinalisL.: behavioural and anticonvulsant properties. Phyther Res. 1996;10:145-51.

26. Upton R, Petrone C (Eds): Valerian Root Valeriana Officinalis Analytical, Quality Control, and Therapeutic Monograph. Santa Cruz, CA: American Herbal Pharmacopoeia (AHP); 1999.

27. Patočka J, Jakl J. Biomedically relevant chemical constituents of Valeriana officinalis. J Appl Biomed. 2010;8:11-8.

28. Gao XQ, Björk L. Valerenic acid derivatives and valepotriates among individuals, varieties and species of Valeriana. Fitoterapia. 2000;71:19-24.

29. Khom S, Baburin I, Timin E, Hohaus A, Trauner G, Kopp B, et al. Valerenic acid potentiates and inhibits $G A B A(A)$ receptors: molecular mechanism and subunit specificity. Neuropharmacology. 2007;53:178-87.

30. Benke D, Barberis A, Kopp S, Altmann K-H, Schubiger M, Vogt KE, et al. GABA A receptors as in vivo substrate for the anxiolytic action of valerenic acid, a major constituent of valerian root extracts. Neuropharmacology. 2009;56:174-81.

31. Del Valle-Mojica LM, Ortíz JG. Anxiolytic properties of valeriana officinalis in the zebrafish: a possible role for metabotropic glutamate receptors. Planta Med. 2012;78:1719-24.

32. Circosta C, De Pasquale R, Samperi S, Pino A, Occhiuto F. Biological and analytical characterization of two extracts from Valeriana officinalis. J Ethnopharmacol. 2007;112:361-7.

33. Mussulini BHM, Leite CE, Zenki KC, Moro L, Baggio S, Rico EP, et al. Seizures induced by pentylenetetrazole in the adult zebrafish: a detailed behavioral characterization. PLoS One. 2013;8, e54515

34. Afrikanova T, Serruys A-SK, Buenafe OEM, Clinckers R, Smolders I, de Witte P a $\mathrm{M}$, et al. Validation of the zebrafish pentylenetetrazol seizure model: locomotor versus electrographic responses to antiepileptic drugs. PLoS One. 2013;8:e54166

35. Wong K, Stewart A, Gilder T, Wu N, Frank K, Gaikwad S, et al. Modeling seizure-related behavioral and endocrine phenotypes in adult zebrafish. Brain Res. 2010;1348:209-15.

36. Baraban SC, Taylor MR, Castro PA, Baier H. Pentylenetetrazole induced changes in zebrafish behavior, neural activity and c-fos expression. Neuroscience. 2005:131:759-68.

37. Baxendale S, Holdsworth CJ, Meza Santoscoy PL, Harrison MRM, Fox J, Parkin $\mathrm{C}$ a, et al. Identification of compounds with anti-convulsant properties in a zebrafish model of epileptic seizures. Dis Model Mech. 2012;5:773-84.

38. Berghmans S, Hunt J, Roach A, Goldsmith P. Zebrafish offer the potential for a primary screen to identify a wide variety of potential anticonvulsants. Epilepsy Res. 2007;75:18-28.

39. Del Valle-Mojica LM, Cordero-Hernández JM, González-Medina G, RamosVélez I, Berríos-Cartagena N, Torres-Hernández B, et al. Aqueous and ethanolic Valeriana officinalis extracts change the binding of ligands to glutamate receptors. Evid Based Complement Alternat Med. 2011;2011:Article ID 891819

40. Gerlai R, Lee V, Blaser R. Effects of acute and chronic ethanol exposure on the behavior of adult zebrafish (Danio rerio). Pharmacol Biochem Behav. 2006;85:752-61. 
41. Hortopan GA, Dinday MT, Baraban SC. Zebrafish as a model for studying genetic aspects of epilepsy. Dis Model Mech. 2010;3:144-8.

42. Norton W, Bally-Cuif L. Adult zebrafish as a model organism for behavioural genetics. BMC Neurosci. 2010;11:90.

43. Fleming A. Zebrafish as an alternative model organism for disease modelling and drug discovery: implications for the 3Rs. Natl Cent Replace Refinement Reduct Anim Res 2007:1-7.

44. Nicholas JM, Ridsdale L, Richardson MP, Ashworth M, Gulliford MC. Trends in antiepileptic drug utilisation in UK primary care 1993-2008: cohort study using the General Practice Research Database. Seizure. 2012;21:466-70.

45. Haroon A, Tripathi M, Khanam R, Vohora D. Antiepileptic drugs prescription utilization behavior and direct costs of treatment in a national hospital of India. Ann Indian Acad Neurol. 2012;15:289-93.

46. Golmohammadi R, Pejhan A, Azhdari-Zarmehri H, Mohammad-Zadeh M. The role of ethanol on the anticonvulsant effect of valproic acid and cortical microvascular changes after epileptogenesis in mice. Neurol Sci. 2013;34:1125-31.

47. Cuttle L, Munns AJ, Hogg NA, Scott JR, Hooper WD, Dickinson RG, et al. Phenytoin metabolism by human cytochrome P450: involvement of P450 $3 \mathrm{~A}$ and $2 \mathrm{C}$ forms in secondary metabolism and drug-protein adduct formation. Drug Metab Dispos. 2000;28:945-50.

48. Miners JO, Birkett DJ. Cytochrome P4502C9: an enzyme of major importance in human drug metabolism. Br J Clin Pharmacol. 1998;45:525-38.

49. Schmider J, Greenblatt DJ, von Moltke LL, Karsov D, Shader RI. Inhibition of CYP2C9 by selective serotonin reuptake inhibitors in vitro: studies of phenytoin p-hydroxylation. Br J Clin Pharmacol. 1997;44:495-8.

50. Andersson T, Miners JO, Veronese ME, Birkett DJ. Diazepam metabolism by human liver microsomes is mediated by both S-mephenytoin hydroxylase and CYP3A isoforms. Br J Clin Pharmacol. 1994;38:131-7.

51. Donovan JL, DeVane CL, Chavin KD, Wang J-S, Gibson BB, Gefroh HA, et al. Multiple night-time doses of valerian (Valeriana officinalis) had minimal effects on CYP3A4 activity and no effect on CYP2D6 activity in healthy volunteers. Drug Metab Dispos. 2004;32:1333-6.

52. Hellum BH, Hu Z, Nilsen OG. The induction of CYP1A2, CYP2D6 and CYP3A4 by six trade herbal products in cultured primary human hepatocytes. Basic Clin Pharmacol Toxicol. 2007;100:23-30.

53. Hellum BH, Hu Z, Nilsen OG. Trade herbal products and induction of CYP2C19 and CYP2E1 in cultured human hepatocytes. Basic Clin Pharmacol Toxicol. 2009;105:58-63.

54. Awad R, Levac D, Cybulska P, Merali Z, Trudeau VL, Arnason JT. Effects of traditionally used anxiolytic botanicals on enzymes of the gammaaminobutyric acid (GABA) system. Can J Physiol Pharmacol. 2007;85:933-42.

55. Oliva I, González-Trujano ME, Arrieta J, Enciso-Rodríguez R, Navarrete A. Neuropharmacological profile of hydroalcohol extract of Valeriana edulis ssp. procera roots in mice. Phytother Res. 2004;18:290-6.

56. Celis CT, Rincón J, Guerrero MF. Pharmacological activity on central nervous system of the ethanolic extract and the alcaloidal fraction of Valeriana pavonii. Rev Col Cienc Quím Farm. 2007;36:11-22.

57. Giraldo SE, Rincón J, Puebla P, Marder M, Wasowski C, Vergel N, et al. Isovaleramide, an anticonvulsant molecule isolated from Valeriana pavonii. Biomedica. 2010;30:245-50

58. Alfaro JM, Ripoll-Gómez J, Burgos JS. Kainate administered to adult zebrafish causes seizures similar to those in rodent models. Eur J Neurosci. 2011;33:1252-5.

59. Wong K, Elegante M, Bartels B, Elkhayat S, Tien D, Roy S, et al. Analyzing habituation responses to novelty in zebrafish (Danio rerio). Behav Brain Res. 2010;208:450-7.

60. Siebel AM, Piato AL, Capiotti KM, Seibt KJ, Bogo MR, Bonan CD. PTZ-induced seizures inhibit adenosine deamination in adult zebrafish brain membranes. Brain Res Bull. 2011;86:385-9.

61. Lee Y, Kim D, Kim Y-H, Lee H, Lee C-J. Improvement of pentylenetetrazolinduced learning deficits by valproic acid in the adult zebrafish. Eur J Pharmacol. 2010;643:225-31.

62. Mares P. Age- and dose-specific anticonvulsant action of bumetanide in immature rats. Physiol Res. 2009;58:927-30.

63. Ginsberg G, Hattis D, Sonawane B, Russ A, Banati P, Kozlak M, et al. Evaluation of child/adult pharmacokinetic differences from a database derived from the therapeutic drug literature. Toxicol Sci. 2002;66:185-200.

\section{Submit your next manuscript to BioMed Central and take full advantage of:}

- Convenient online submission

- Thorough peer review

- No space constraints or color figure charges

- Immediate publication on acceptance

- Inclusion in PubMed, CAS, Scopus and Google Scholar

- Research which is freely available for redistribution

Submit your manuscript at www.biomedcentral.com/submit 